\title{
Adaptive phenotypic plasticity of eel diadromy
}

\author{
Eric Edeline* \\ Cemagref, Unité Ecosystèmes Estuariens et Poissons Migrateurs Amphihalins (EPBX), 50 Avenue de Verdun, \\ 33612 Cestas Cedex, France \\ Present address: Centre for Ecological and Evolutionary Synthesis, Department of Biology, University of Oslo, \\ PO Box 1066, Blindern, 0316 Oslo, Norway
}

\begin{abstract}
Eels are marine teleosts that have ancestrally evolved a continental growth phase during which diadromy is facultative. This migratory plasticity reflects a fitness trade-off between search for the most productive habitats and competition avoidance favoring shift to less productive areas, while migration costs (increased mortality and reduced growth) hinder movements. To cope with these conflicting selective pressures acting in heterogeneous and unpredictable environments, eels have evolved a conditional evolutionarily stable strategy (ESS) with alternative tactics as a regulation mechanism for migratory plasticity. In this model, diadromy is considered as a threshold reaction norm to an individual's energetic status. In the population, this reaction norm evolves rapidly in response to changes in the cost/benefit fitness ratio of diadromy. This conditional ESS model may explain how the collapse of freshwater eel stocks results not only from decreased recruitment but also from an adaptive drop in the proportion of the diadromous phenotype in populations. Hence, I suggest that the decline in populations of eels has been less steep in salt than in freshwater habitats.
\end{abstract}

KEY WORDS: Anguilla spp. · Diadromy · Dispersal · Game theory · Migration · Phenotypic plasticity · Population decline $\cdot$ Rapid evolution

Resale or republication not permitted without written consent of the publisher

\section{INTRODUCTION}

Eels Anguilla spp. are semelparous marine fishes belonging to the elopomorph superorder, a group of phylogenetically ancient teleosts. Eels migrate between marine breeding and continental feeding areas where they grow for 3 to $20 \mathrm{yr}$ (yellow stage) before beginning gonad maturation (silvering) and engaging in the spawning migration. Eels colonize an extremely wide variety of growth habitats including the littoral zone, estuaries, marshes (salt or fresh), rivers and lakes. Such ubiquity is almost unique among teleost fishes and results from an extreme migratory plasticity (Tsukamoto \& Arai 2001, Daverat et al. 2006). However, the mechanisms controlling this plasticity remain largely unknown. Eel recruitment in freshwater habitats is crashing worldwide, raising well-founded concern about possible extinction of these legendary fishes (Dekker et al. 2003, Stone
2003). In this context, it is urgent to synthesize and improve knowledge for both ecological and conservation purposes. The aim of this essay is to provide an evolutionary mechanism for eel migratory plasticity. I apply the principles of game theory to analyze the alternative eel phenotypes in terms of cost and benefits to evolutionary fitness. For greater convenience, I will dichotomize these alternative migratory histories as diadromy, i.e. migration in freshwater (FW), vs. nondiadromy, i.e. settlement in saltwater (SW).

\section{BENEFITS OF DIADROMY: HABITAT PRODUCTIVITY VS. COMPETITION AVOIDANCE}

It is widely admitted that diadromy in fishes has evolved in response to gradients in food availability between marine and FW habitats. At low latitudes, the higher primary productivity of FW habitats may favor a 
FW growth period by marine species; in contrast, at high latitudes, a marine growth phase may be advantageous for FW species (Gross et al. 1988). The genus Anguilla originates from tropical oceans where it probably developed diadromy (Tsukamoto et al. 2002), which may therefore be viewed as an ancestral trait. The shift of some Anguilla species to temperate latitudes promoted the evolution of a facultative diadromy (Tsukamoto \& Arai 2001), likely because of the decreased relative productivity of rivers compared with the sea and estuaries. In Taiwan, where both tropical and temperate species co-occur (at the margins of both geographical ranges), the tropical $A$. marmorata inhabits the upper river reaches, while the temperate $A$. japonica mainly colonizes the estuary and the lower river reaches (Shiao et al. 2003). Indeed, A. marmorata elvers migrate up-river much more rapidly than temperate elvers (Robinet et al. 2003), consistent with the hypothesis that eels evolve a migratory behavior in response to the relative habitat productivity prevailing in their geographical range.

At first glance, colonization of FW habitats by temperate eels could be seen as a paradox: why maintain ancestral diadromy if productivity is higher in saline environments? In light of all evidence, diadromy allows reduction of both inter- and intra-specific competition, 2 pivotal components of migration and dispersal evolution (Clobert et al. 2001). Indeed, shift to FW probably allows temperate eels to avoid both strong marine predators, such as conger eels, and the high densities of conspecifics produced in brackish waters by intense primary productivity and limited habitat surface (Tesch 1977, Moriarty 2003). Therefore, evolution of eel migration may be driven by a trade-off between search for the most productive habitats and shift to less productive, lower density habitats. In Anguilla anguilla, the gut develops for osmoregulation in FW whatever the ambient salinity (Ciccoti et al. 1993), indicating ontogenetic programming for osmoregulation in FW. This suggests that diadromy remains the favored migratory tactic in A. anguilla, i.e. that competition avoidance is more prominent than relative habitat productivity in driving evolution of migration under temperate latitudes.

\section{ENERGETIC COSTS OF DIADROMY: INCREASED MORTALITY, REDUCED GROWTH}

Bioenergetics strongly constrain the evolution of migration (Bernatchez \& Dodson 1987). Indeed, migration-induced exhaustion may lead to death, either directly or through reduced competitive ability and increased sensitivity to predation and infection (Clobert et al. 2001). Therefore, energetic limitations represent an immediate constraint for migrants, especially when they are non-feeding and have limited swimming capacities, as do glass eels. Accordingly, recent data from both the laboratory and field indicate that the energetic status controls migratory behavior in glass eels. First, sedentary individuals in an experimental flume are shorter than swimmers (Bardonnet et al. 2003). Second, under constant experimental conditions, glass eels switch from FW- to SW-preference as their body condition decreases (Edeline et al. 2006). Third, glass eels that precociously settle in the estuary are lighter than river colonizers (Edeline et al. 2004). These data strongly support the view that glass eels migration is conditional on the fact that individuals have sufficient energy stores with which to migrate, as also observed in juvenile salmonids (Forseth et al. 1999, Thériault \& Dodson 2003).

In addition to an immediate survival problem, the energetic cost of migration may have consequences on the longer term because migratory and foraging behaviors are in direct opposition in eels. Indeed, digestion and locomotion compete for energy and oxygen allocation, indicating that a feeding individual cannot migrate and vice versa (Owen 2001). Also, benthic foraging behavior by yellow eels requires territoriality (Bertin 1951), and a migratory individual cannot defend a territory. Therefore, a dual physiological and behavioral conflict between migration and foraging induces reduced or arrested growth during migration periods. This conflict was confirmed under experimentally controlled conditions where the glass eel migratory propensity was negatively correlated with juvenile growth performance over a period of 2 mo (Edeline et al. 2005). Hence, diadromy in the eel may be seen as a risky investment tactic: migrants lose immediate fitness through reduced growth but invest in future fitness gain through competition avoidance.

\section{CONDITIONAL EVOLUTIONARILY STABLE STRATEGY (ESS) MODEL}

The term 'conditional strategy' is used in evolutionary game theory to define a type of phenotypic plasticity in which a single individual can express different phenotypes (the tactics of the conditional strategy) depending on its environmental, social and physiological status (cueing trait). Based on the above cost and benefits analysis, I suggest that eel diadromy is a conditional strategy cued by individual energetic status, i.e. individual eels choose the migratory tactic (diadromy vs. non-diadromy) that maximizes fitness depending on the level of their energy stores (Edeline 2005) (Fig. 1). Indeed, diadromy is the most beneficial tactic for individuals with high energetic status be- 


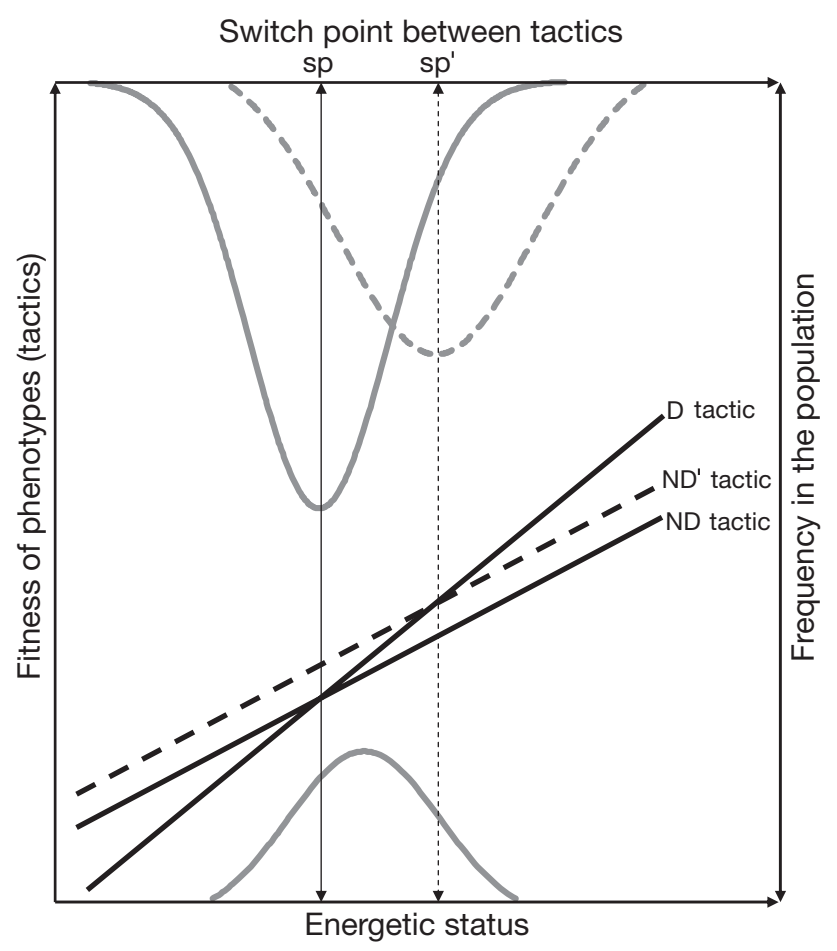

Fig. 1. Anguilla anguilla. Conditional ESS model for alternative migratory tactics in glass eels (D: Diadromy, ND: NonDiadromy), after Hazel et al. (1990, 2004) and Gross (1996). Fitness functions of the tactics D and ND are status-dependent owing to the trade-off between costs and benefits of diadromy. First, consider only black solid lines. High-energeticstatus glass eels have the capacity to migrate and will gain the highest fitness by migrating to low-competition river habitats. In contrast, low-energetic-status glass eels are already exhausted and cannot fuel migration without seriously impairing their immediate survival and competitive ability. They will thus gain highest fitness from settling in saline habitats. Individuals switch between tactics where fitness functions cross: the ESS switch point (sp). Second, consider only grey solid curves referring to trait distributions in the population (right-hand vertical axis). Because both energetic status and sp are polygenic traits influenced by environmental variation, they are normally distributed in the population and $\mathrm{sp}$ is therefore a mean switch point. The proportion of each phenotype (diadromous vs. non-diadromous) in the population is determined by the distribution of switch points (upper horizontal axis) relative to the distribution of energetic status (lower horizontal axis). Here the mean switch point is lower than the mean energetic status, resulting in a majority of migrants in the population. Note that the variation for switch points is larger than variation for energetic status in the population, leading to existence of unconditional migrants and unconditional sedentary individuals (Hazel et al. 2004). Finally, consider only dashed lines and curves. Decreased recruitment during the last decades, which has lowered population densities in downstream habitats, has increased fitness return of the ND tactic to ND'. This change in evolutionary equilibrium induces a displacement of $\mathrm{sp}$ to $\mathrm{sp}^{\prime}$, and thus decreases the proportion of glass eels migrating to FW. Reduced selection against non-diadromy decreases the strength of stabilizing selection and most likely increases variance of the switch point distribution (Futuyma 1998). Because the surface below the curve is held constant, the peak of the curve decreases cause it allows competition avoidance. However, as energetic status decreases, costs of diadromy increase and eventually outweigh its benefits. Tactics change at that point where fitness benefits switch from favoring one tactic to favoring the alternative: the ESS switch point. The strategic model of Gross (1996) is particularly illustrative. I have here combined this model with the quantitative genetic model developed by Hazel et al. (2004), which allows inheritance of both the cueing trait and switch point, and coexistence of both conditional and unconditional individuals in the population (Fig. 1). The switch point and the cueing trait are allowed to vary both within and among individuals. At the individual level, the switch point and the cueing trait are genetically fixed and vary only in response to environmental effects (temperature, trophic and demographic parameters etc.). However, at the population level, variations in the switch point and the cueing trait result from both additive genetic and non-genetic sources (Hazel et al. 1990, 2004, Roff 1996, Garant et al. 2003), giving rise to normal distributions for both traits (grey curves in Fig. 1). The proportion of each alternative phenotype in the population (D vs. ND in Fig. 1) is controlled by the distribution of switch points relative to the distribution of the cueing trait.

In Fig. 1, I illustrate how Anguilla anguilla glass eels maximize their fitness by either migrating to FW habitats or settling in SW habitats, depending on their energetic status. The conditional ESS model presented here may be extended to other behaviors and developmental stages. For instance, in non-migratory yellow eels, individual status also depends on body size, which conditions the hierarchy in agonistic interactions. Residency is favored in (large) dominant eels, while (small) subordinate eels derive higher fitness from dispersal towards habitats where competition is less strong. The model may also be used to qualitatively predict evolution of diadromy under changing selective pressures. For instance, lowered population densities in SW habitats owing to population decline will increase fitness return from the non-diadromy tactic, and result in a shift to the right and increased variance in the distribution of switch points (as illustrated in Fig. 1). Hence, I suggest that decreased recruitment over the last 2 decades has not only decreased the number of migrants, but also their proportion in the population. Another prediction from the model is that river colonizers should now have higher energetic status than before population collapse.

Now, consider anthropogenic changes that act selectively on FW habitats, e.g. dam construction, wetland drainage, fishing and pollution. These artificial selective pressures will increase selection against migrants, lower the D fitness function and thus further push the 
distribution of switch points to the right, i.e. further reduce the proportion of migrants in the population. Note that if you also consider selection on the cueing trait (against high energetic status), the decrease in the proportion of migrants will be even stronger. In conclusion, diadromy in eels may be viewed as a threshold reaction norm to a high energetic status, favored by selection when the cost/benefit fitness ratio of diadromy is low. Increase in this ratio during the last few decades induced a rapid evolutionary shift in the reaction norm and consequently reduced the proportion of diadromous phenotypes in populations. Long-term time series of marine eel abundances would allow the hypothesis that population decline has been less steep in SW than in FW to be tested.

Acknowledgements. I thank Philippe Gaudin (INRA) for fruitful discussions and Asbjørn Vøllestad (University of Oslo) for comments on an early version of the manuscript. I was supported by research grants from the Cemagref, Région Aquitaine and the French Ministère de l'Ecologie.

\section{LITERATURE CITED}

Bardonnet A, Dasse S, Parade M, Heland M (2003) Study of glass-eels movements in a flume in relation to nycthemeral changes. Bull Fr Pêche Piscic 368:9-19

Bernatchez L, Dodson JJ (1987) Relationship between bioenergetics and behavior in anadromous fish populations. Can J Fish Aquat Sci 44:399-407

Bertin L (1951) Les anguilles. Payot, Paris

Ciccoti E, Macchi E, Rossi A, Cataldi E, Cataudella S (1993) Glass eel (Anguilla anguilla) acclimation to freshwater and seawater: morphological changes of the digestive tract. J Appl Ichthyol 9:74-81

Clobert J, Danchin E, Dhondt AA, Nichols JD (2001) Dispersal. Oxford University Press, Oxford

Daverat F, Limburg KE, Thibault I, Shiao JC and 5 others (2006) Phenotypic plasticity of habitat use by three temperate eel species, Anguilla anguilla, A. japonica and A. rostrata. Mar Ecol Prog Ser 308:231-241

Dekker W, Casselman JM, Cairns DK, Tsukamoto K, Jellyman D, Lickers H (2003) Worldwide decline of eel resources necessitates immediate action. Fisheries 28:28-30

Edeline E (2005) Facteurs du contrôle de la dispersion continentale chez l'anguille. PhD thesis, CEMAGREF/University of Toulouse III

Edeline E, Dufour S, Briand C, Fatin D, Elie P (2004) Thyroid status is related to migratory behavior in Anguilla anguilla glass eels. Mar Ecol Prog Ser 282:261-270

Editorial responsibility: Howard Browman (Associate Editorin-Chief), Storebø, Norway
Edeline E, Dufour S, Elie P (2005) Role of glass eel salinity preference in the control of habitat selection and growth plasticity in Anguilla anguilla. Mar Ecol Prog Ser 304: 191-199

Edeline E, Lambert P, Rigaud C, Elie P (2006) Effects of body condition and water temperature on Anguilla anguilla glass eels migratory behavior. J Exp Mar Biol Ecol 331: 217-225

Forseth T, Naesje TF, Jonsson B, Harsaker K (1999) Juvenile migration in brown trout: a consequence of energetic state. J Anim Ecol 68:783-793

Futuyma DJ (1998) Evolutionary biology. Sinauer, Sunderland, MA

Garant D, Dodson JJ, Bernatchez L (2003) Differential reproductive success and heritability of alternative reproductive tactics in wild Atlantic salmon (Salmo salar L.). Evolution 57:1133-1141

Gross MR (1996) Alternative reproductive strategies and tactics: diversity within sexes. Trends Ecol Evol 11:92-98

Gross MR, Coleman RM, McDowall RM (1988) Aquatic productivity and the evolution of diadromous fish migration. Science 139:1291-1293

Hazel WN, Smock R, Johnson MD (1990) A polygenic model for the evolution and maintenance of conditional strategies. Proc R Soc Lond B 242:181-187

Hazel W, Smock R, Lively CM (2004) The ecological genetics of conditional strategies. Am Nat 163:888-900

Moriarty C (2003) The yellow eel. In: Aida K, Tsukamoto K, Yamauchi K (eds) Eel biology. Springer, Tokyo, p 89-105

Owen SF (2001) Meeting energy budgets by modulation of behaviour and physiology in the eel (Anguilla anguilla L.). Comp Biochem Phys A 128:629-642

Robinet $\mathrm{T}$, Guyet S, Marquet G, Mounaix B, Olivier JM, Tsukamoto K, Valade P, Feunteun E (2003) Elver invasion, population structure and growth of marbled eels Anguilla marmorata in a tropical river on Réunion Island in the Indian Ocean. Environ Biol Fish 68:339-348

Roff DA (1996) The evolution of threshold traits in animals. Q Rev Biol 71:3-35

Shiao JC, lizuka Y, Chang CW, Tzeng WN (2003) Disparities in habitat use and migratory behavior between tropical eel Anguilla marmorata and temperate eel A. japonica in four Taiwanese rivers. Mar Ecol Prog Ser 261:233-242

Stone R (2003) Freshwater eels are slip-sliding away. Science 302:221-222

Tesch FW (1977) The eel. Chapman \& Hall, London

Thériault V, Dodson JJ (2003) Body size and the adoption of a migratory tactic in brook charr. J Fish Biol 63: $1144-1159$

Tsukamoto K, Arai T (2001) Facultative catadromy of the eel Anguilla japonica between freshwater and seawater habitats. Mar Ecol Prog Ser 220:265-276

Tsukamoto K, Aoyama J, Miller JM (2002) Migration, speciation, and the evolution of diadromy in anguillid eels. Can J Fish Aquat Sci 59:1989-1998

Submitted: December 6, 2006; Accepted: January 23, 2007

Proofs received from author(s): June 22, 2007 